\title{
A VOLTA AOS PERIÓDICOS
}

\section{The Return of the Journals}

Prof. Dr. Eustógio Wanderley Correia Dantas

Programa de Pós-Graduação em Geografia/UFC

Campous do PPici, Bloco 911, CEP: 60355-760, Fortaleza, CE - Brasil

Tel: (+55 85) 33669855 - edantas@ufc.br

\section{${ }_{a} a \boldsymbol{a} a a$}

\section{Resumo}

A expansão dos programas de pós-graduação em Geografia resultou na universalização da produtividade científica e consequente reestruturação dos seus veículos, em revistas especial o especialista, que têm assumido um papel principal na política de avaliação acadêmica. Isso desafia o nosso pensamento e exige reflexão sobre a natureza eo comportamento atual dessas publicações em escala nacional. Com base nos dados da revisão CAPES para o período 2007-2009, desenvolvemos uma análise capaz de identificar as tendências impostas sobre o traçado das revistas acadêmicas especializadas em pesquisa de geografia.

Palavras-chave: produtividade científica, pós-graduação, periódicos.

\begin{abstract}
The expansion of graduate programs in Geography has resulted in the universalization of scientific productivity and consequent restructuring of its vehicles, in particular the specialist journals, which have assumed a principal role in academic evaluation policies. This challenges our thinking and demands reflection on the nature and current behavior of these publications on a national scale. Based on the data from the CAPES review for the period 2007-2009, we developed an analysis capable of identifying the tendencies imposed on the delineation of academic journals specialized in geography research.
\end{abstract}

Key words: scientific productivity, graduate studies, journals.

\section{Resumen}

La expansión de la Post-graduación en Geografía induce el proceso de universalización de la producción científica y consecuentemente redimensiona los vehículos, dentro de los cuales los periódicos adquieren un papel de peso en la política de evaluación emprendida, revirtiendo mentalidades e imponiendo necesidades de reflexión sobre su naturaleza y comportamiento contemporáneo a escala nacional. Pactado en los datos de recolección CAPES 2007-2009, emprenderemos un análisis capaz de aprender las tendencias puestas en el delineamiento de este vehículo en el área de la Geografía.

Palabras-clave: producción científica, post-graduación, periódicos.

\section{$a a \boldsymbol{a} a a$}




\section{INTRODUÇÃO}

Processo de consolidação da Pós-Graduação em Geografia em escala nacional induz, nos últimos decênios, importante redimensionamento da produção científica docente. De forte concentração espacial, tem-se, principalmente no pós anos 2000, implementação de política de expansão a atingir a quase totalidade do território nacional e cujos desdobramentos apontam para o fortalecimento da produção científica brasileira em seus diversos veículos: Anais de Eventos, Teses e Dissertações, Livros (coletâneas, textos integrais e capítulos) e Periódicos.

Da escola fundadora, Universidade de São Paulo com os cursos de Geografia Física e Humana, ambos criados em 1971 (mestrado e doutorado), das pioneiras UFRJ (mestrado em 1972 e doutorado em 1992), UNESP de Rio Claro (mestrado em 1977 e doutorado em 1983) e UFPe (mestrado em 1976 e doutorado em 2003), atualmente conta-se com 46 cursos de mestrado, distribuídos em todas as regiões brasileiras, e 21 cursos de doutorado, implantados, em ordem crescente, no Sudeste (10 cursos), Nordeste (5 cursos), Sul (4 cursos) e Centro Oeste (2 cursos) do país (quadro 1). A citada expansão induz universalização da produção científica e consequente redimensionamento dos veículos de divulgação. Anais de Eventos passam por processo de massificação, perdendo gradativamente em importância; a produção de dissertações se consolidada, grosso modo, na totalidade do território (Figura 1), as teses se concentram, com mais força, nas áreas com cursos já consolidados (Sudeste, Sul, Nordeste e Centro Oeste) (Figura 1); a produção de coletâneas, textos integrais e capítulos de livro também ganha força em escala nacional (Figura 2); a produção de periódicos não foge à regra, ultrapassando em termos quantitativos, como veremos na sequência, a produção em veículo livros.

Quadro 1 - Criação dos Cursos de Pós-Graduação em Geografia por Região e Universidade: decênios de 1970, $1980,1990,2000$ e 2010

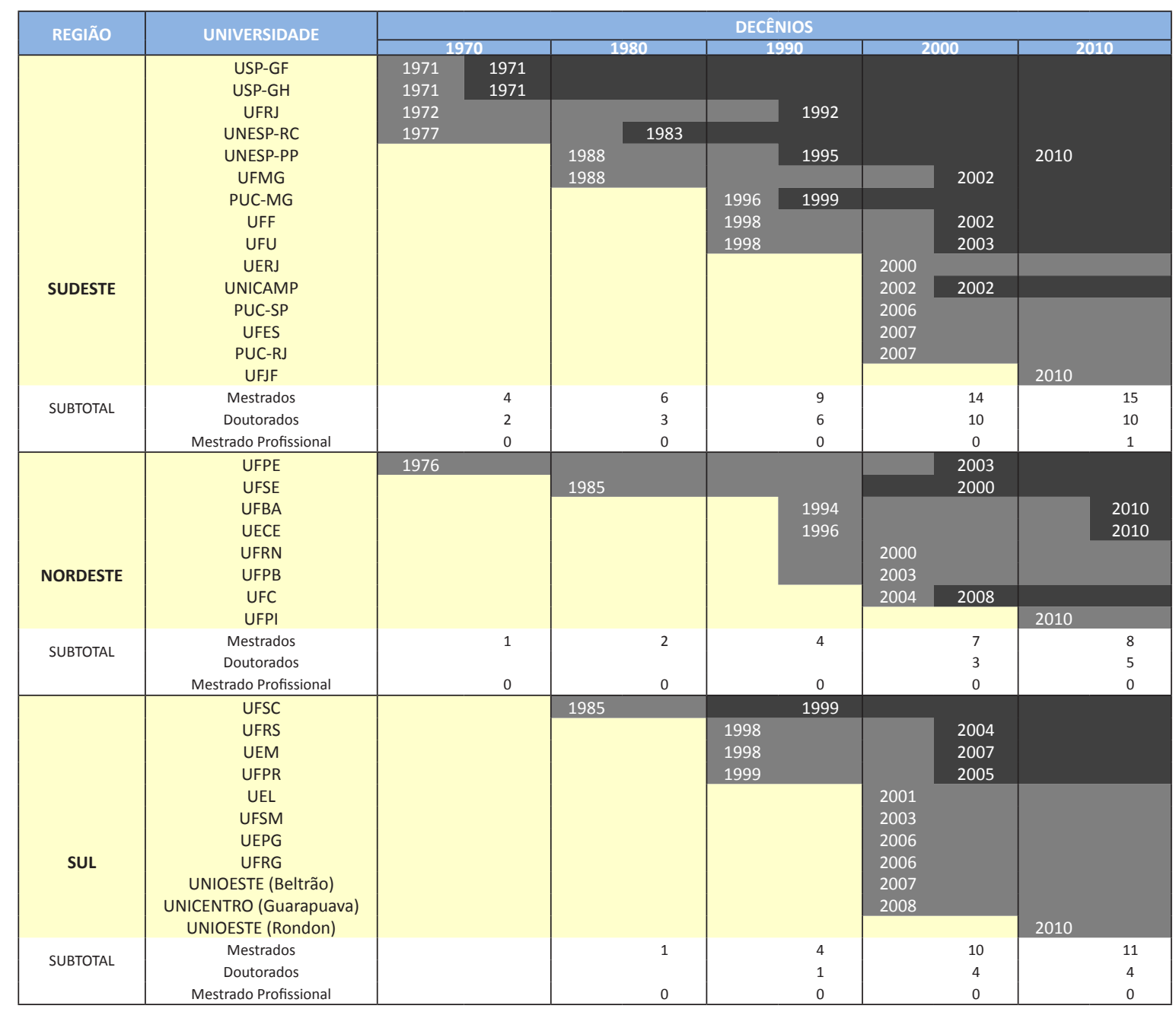




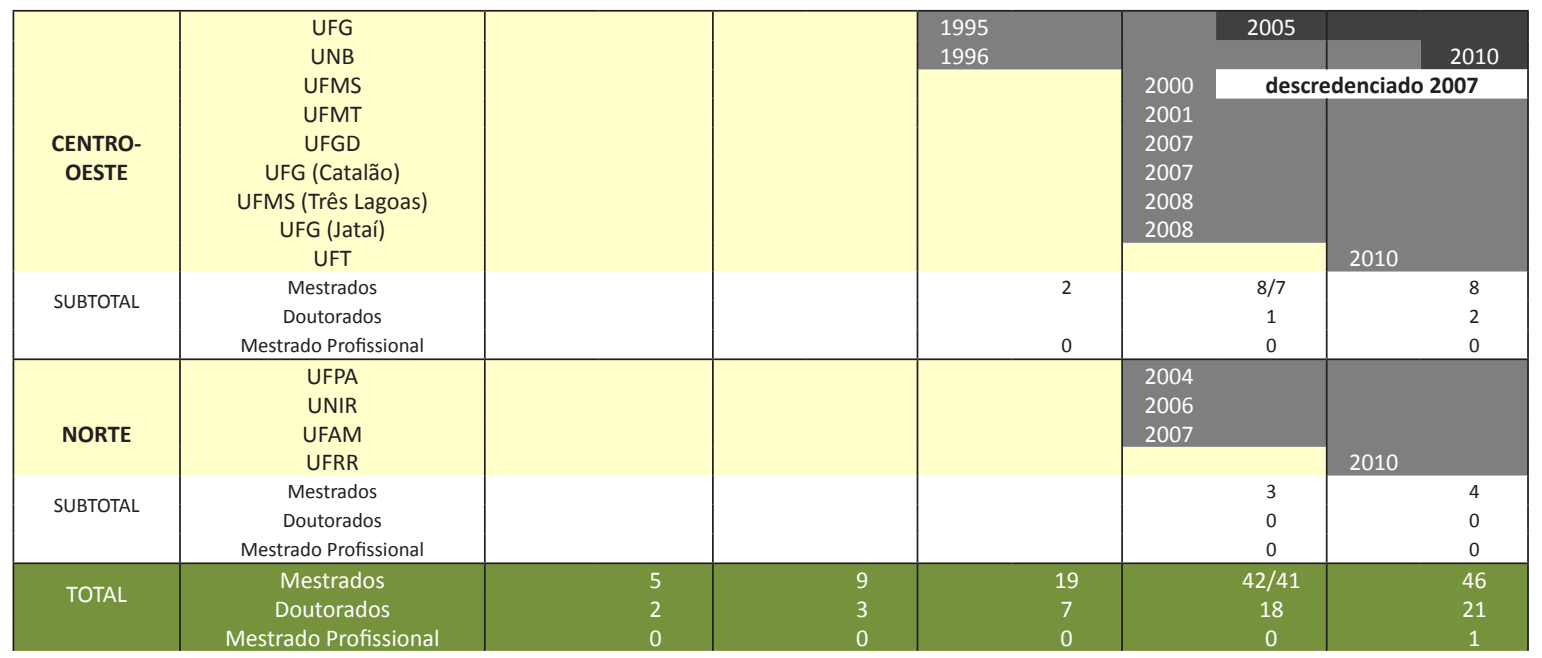

Fonte: CAPES

Organizado Por: SILVA, José Borzacchiello; DANTAS, Eustógio Wanderley Correia

Induzido por política de avaliação adotada na Pós-Graduação Brasileira, os periódicos assumem papel basilar na lógica de consolidação dos programas de pós-graduação em geografia, revertendo mentalidades pré-existentes e impondo necessidade de desenvolvimento de estudos sobre sua natureza e comportamento na escala nacional, bem como seus desdobramentos no âmbito regional e estadual.

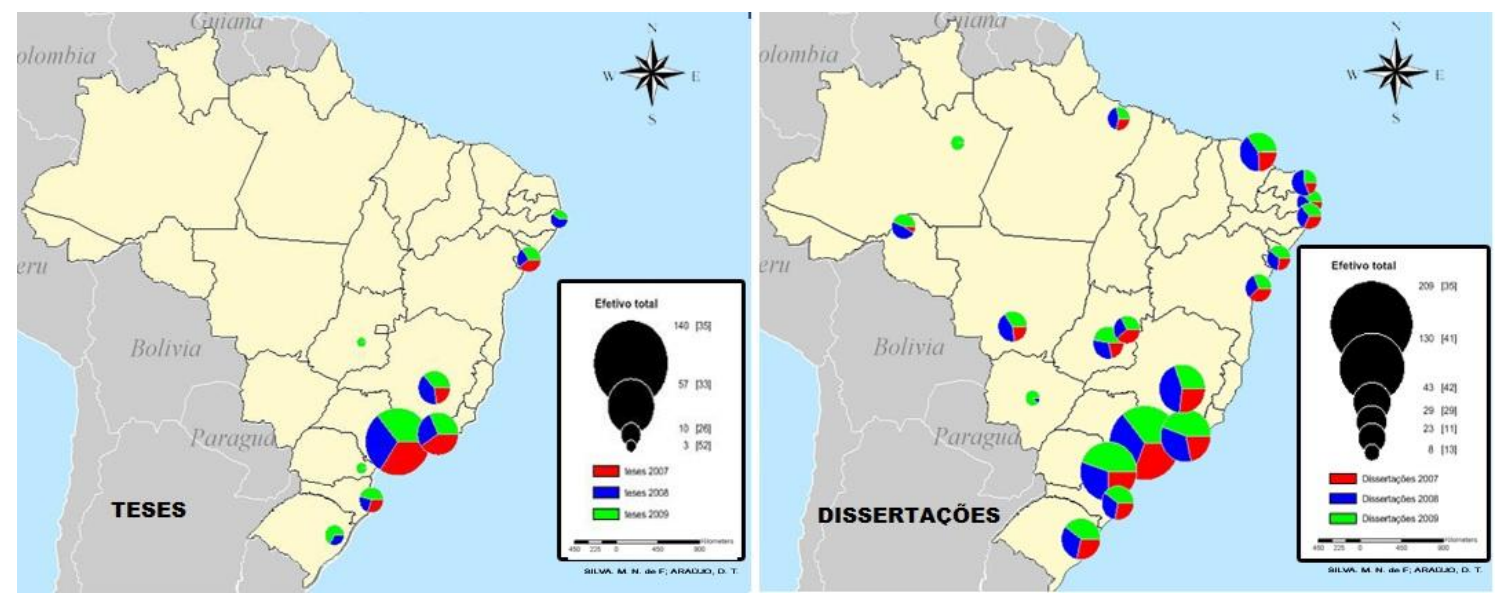

Figura 1 - Teses e Dissertações Produzidas na Pós-Graduação em Geografia Por Estado: 2007 a 2009 Fonte: Coleta CAPES - 2007 a 2009
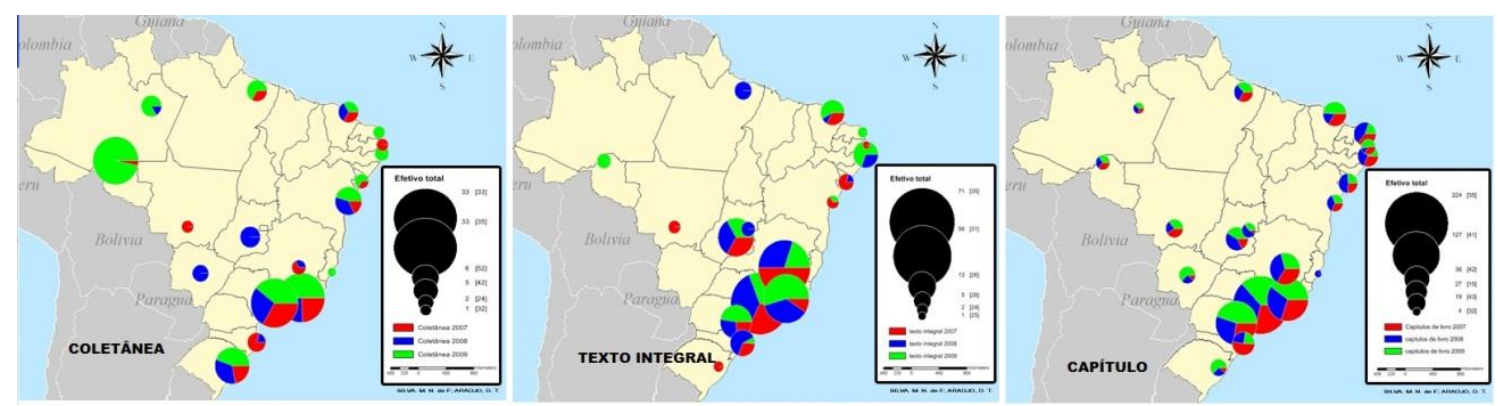

Figura 2 - Produção Derivada do Veículo Livro, na Pós-Graduação em Geografia, Por Estado: 2007 a 2009 Fonte: Coleta CAPES - 2007 a 2009 
O presente texto objetiva realizar um ensaio analítico, não conclusivo, capaz de representar espacialmente a citada produção. $\mathrm{O}$ intuito será o de apreender seu comportamento contemporâneo e dele abstrair algumas tendências postas e que ultrapassam os domínios da própria geografia e das ciências sociais.

\section{UM PEQUENO RECUO NO TEMPO}

Nos primórdios da geografia brasileira, os periódicos tinham papel de destaque dentre os demais veículos, contribuindo sobremaneira na construção e fortalecimento do pensamento geográfico em escala nacional: tanto a Revista do IBGE (base das análises e contribuições dos geógrafos na construção de uma escola nacional, mas também a contar com contribuição de nomes internacionais da Geografia) e os Boletins de Geografia (signatários de uma Associação de Geógrafos combativa).

Com o tempo a citada lógica é fragilizada com potencialização de uma produção autoral e alicerçada nas editoras: nos primórdios a Editora DIFEL, com tradução de textos clássicos franceses, e a HUCITEC (SP), a investir maciçamente na produção de obras de Geografia, e mais recentemente a CONTEXTO (SP) e a ANNABLUME (RJ), sem desmerecer a inclusão, nesta listagem, das editoras das universidades. A exemplo das ciências sociais, sua produção se volta a um público amplo e desejoso de informações sobre o território nacional, grosso modo, suas histórias, suas geografias...

Nestes termos, apresenta-se quadro diferenciado do notado nas ciências exatas, naturais, biológicas e sociais aplicadas, cujo constructo do conhecimento jamais abdicou ou minimizou o veículo periódico. Pelo contrário, o fortaleceu no tempo, veiculando a produção brasileira em escala internacional, leia-se disponibilizada em periódicos estrangeiros de peso. De conhecimento estratégico na modernização do país, corresponde a gênero de produção dependente diretamente das pesquisas realizadas em escala internacional e publicizadas na língua inglesa.

Logo, pode-se afirmar que os parâmetros norteadores dos estudos desenvolvidos pelos pesquisadores associados a estas ciências são internacionais, esmerando-se cada um deles em decifrar a cultura global dos "papers". Num primeiro momento a escrita, com domínio do inglês ou a dispor de apoio de especialistas em traduções. Num segundo momento, apreendendo rapidamente lógica de rankeamento dos periódicos: fator de impacto, reflexo e determinante da inclusão em dados indexadores.

\section{FIM DA TOLERÂNCIA: A CAMINHO DO FORTALECIMENTO DOS PERIÓDICOS NA ÁREA DE GEOGRAFIA}

No Brasil, os dois percursos indicados convivem e se toleram mutuamente até final dos anos 1990, momento em que o modelo de educação superior europeu perde competitividade internacional, induzindo movimento cujos desdobramentos atingem, principalmente, as ciências sociais em escala internacional.

A partir da assinatura da Declaração de Bolonha (19.06.1999), o modelo de ensino superior europeu passa por grandes transformações: adoção de ciclos de estudo condizentes ao "máster" e "doctorat", aceitação-adoção da língua inglesa na formação dos alunos, adoção de parâmetro de avaliação centrado na produção científica.

Como se tratava de modelo a influenciar fortemente parcela da ciência brasileira, sua derrocada tem implicações no constructo da ciência em escala nacional. A convivência e tolerância perdem força. No seio das instituições de fomento e pesquisa, a lógica intrínseca das "ciências duras" (leia-se ciências exatas, naturais, biológicas e sociais aplicadas) se coloca com força.

Convém destacar que o cerne do embate não se dá nos mesmos termos do caso europeu. A influência americana na formação do ensino superior brasileiro ameniza o embate, restringindo-o, grosso modo, à necessidade de adoção de parâmetros de avaliação da produção científica 
nas ciências sociais. Neste quesito o veículo utilizado toma importância, impondo-se racionalidade que lenta e gradualmente reforça o poder do periódico em relação aos demais veículos: livros, capítulos de livros e coletâneas.

O palco privilegiado das discussões é a CAPES, fórum no qual as representações de áreas intentam fazer prevalecer suas racionalidades. Melhores adaptados à lógica internacional, o discurso dos representantes das ciências duras dispõe de maior força. Entretanto, a instituição de práticas democráticas no país possibilita uma passagem negociada. A primeira conquista obtida foi a da implementação do Qualis Livro no processo de avaliação da Pós-Graduação brasileira.

No início do primeiro round (triênio 2004-2006), é estabelecido critério de classificação a tornar possível análise comparativa e aproximativa da produção em foco com a dos periódicos. Com o Qualis Livro, o veículo livro (coletâneas, textos integrais e capítulos de livros) é avaliado conforme os mesmos extratos utilizados na classificação dos periódicos: internacional, nacional e local, cada um deles oscilando em três níveis de importância: a b, e c. A única diferença tolerada é a dos procedimentos de avaliação adotados. Nas ciências sociais, os responsáveis pela implementação de processo avaliativo são os representantes de área, com liberdade na adoção de critérios próprios e intransferíveis para as ciências vizinhas. A título de exemplo, na área de geografia o veículo livro foi analisado conforme: aspecto formais de cada uma das obras e aspectos qualitativos resultantes da leitura realizada por consultores ad hoc devidamente indicados. Tal procedimento cria um ranking de qualificação da produção científica a aproximar o veículo livro do periódico.

No final do segundo round (triênio 2007-2009), os procedimentos supramencionados são revistos, com implementação de novos extratos, diferenciando a produção conforme os veículos: periódico (A1, A2, B1, B2, B3, B4, B5 e C) e livro (L4, L3, L2 e L1). Tal tipologia é um resultado da constatação de que a produção científica na contemporaneidade envolve constructo tecnológico (pautado no mundo cibernético) a disponibilizar as produções em escala global. Trata-se de um aspecto positivo, mas cujos desdobramentos apontam para uma diferenciação dos veículos. Nesta perspectiva, livros e periódicos externariam procedimentos avaliativos diferenciados. O primeiro a centrar-se nas representações de área e a consistir em veículo estratégico nas ciências sociais. O segundo pautado predominantemente na racionalidade dos indexadores, dado facilmente assimilado pelas ciências duras, mas a denotar quadro de dificuldade enfrentado nas ciências sociais.

Na análise da produção científica brasileira fica evidente a diferenciação comentada. A produção voltada aos periódicos, além de contar para os programas, valida e qualifica a produção individualizada. Já aquela direcionada aos livros, além de considerar procedimentos e extratos diferenciados, somente é computada na escala dos programas. O veículo livro gera pontuação aos programas, não sendo a "qualificação" obtida pelos autores.

Como consequência direta desta diferenciação, acredita-se, no final do século XX - início século XXI, haver implementação de processo de mudança de mentalidade reinante nas ciências sociais. De produção centrada predominantemente no veículo livro, percebe-se migração rápida e gradual da produção científica para o veículo periódico.

Em quadro representativo da produção científica de 2002 a 2004 (SILVA; DANTAS, 2005) a citada tendência já se apresentava na geografia . Da produção envolvendo 531 docentes associados às pós-graduações em geografia, 2.067 delas foram direcionadas a periódicos, contra $1.189 \mathrm{em}$ capítulos de livros e 494 textos integrais. Tal tendência persiste no triênio 2007-2009, contando as pós-graduações com 838 docentes a publicarem: 2.124 trabalhos em periódicos, 1.917 em capítulos de livros e 288 textos integrais (Tabela 1). 
Tabela 1 - Produção Científica Por Docente: períodos 2002 a 2004 e 2007 a 2009

\begin{tabular}{c|c|c|c|c}
\multirow{2}{*}{ PERÍODO } & \multirow{2}{*}{$\begin{array}{c}\text { Número } \\
\text { Docentes }\end{array}$} & $\begin{array}{c}\text { Texto } \\
\text { Integral }\end{array}$ & Capítulos & \multirow{2}{*}{$\begin{array}{c}\text { Artigos } \\
\text { Periódicos }\end{array}$} \\
\hline $2002-2004$ & 531 & 494 & 1.189 & 2.067 \\
\hline $2007-2009$ & 838 & 288 & 1.917 & 2.124 \\
\hline
\end{tabular}

Fonte: Pesquisa direta Curriculun Lattes Cnpq (2002 a 2004) e Coleta CAPES (2007 a 2009).

Desta constatação quantitativa poder-se-ia afirmar que a área incorpora a racionalidade reinante nas ciências duras ? Pautado em nossa tese principal, pode-se afirmar veementemente que as ciências sociais incorporaram a idéia de classificação, mas a tornam, grosso modo, um atributo dos representantes de área ou, na melhor das hipóteses, aos indexadores nacionais.

Foge-se, desta forma, à tônica reinante nas ciências duras: pautada nos indexadores internacionais, dado que nos leva a ponderar sobre seus desdobramentos na geografia.

\section{DIMENSÃO ESPACIAL DOS PERIÓDICOS NA ÁREA DE GEOGRAFIA E SEU IMPACTO NA PRODUÇÃO CIENTÍFICA BRASILEIRA}

O tratamento dos dados disponibilizados no último coleta CAPES (2007-2009) podem auxiliar na análise ora pretendida. Não se pretende com isto esgotar a discussão, mas pura e simplesmente apontar elementos de reflexão a auxiliarem no delineamento dos caminhos a seguir em nossa ciência. Neste sentido foram considerados dados quantitativos, associados à produção em periódicos, bem como sua dimensão qualitativa, expressa na classificação de cada um dos veículos pela área e, principalmente, conforme os extratos superiores.

Consideramos na análise 2.124 artigos de periódicos divididos nos extratos A1, A2, B1, B2, B3, B4, B5 e C, a contarem, respectivamente, com participação relativa na ordem de 4,00\%, $10,00 \%, 12,00 \%, 17,00 \%, 14,00 \%, 15,00 \%, 19,00 \%$ e 9,00\% (Quadro 1). Na caracterização do comportamento da produção científica na área, percebe-se: maior participação na produção total na frequência de B3 a B5 (48,00\%), seguida de B1 a B2 (29,00\%) e, por último, de A1 e A2 (14,00\%); concentração de $9,00 \%$ da produção em periódicos não qualificados (C)(Quadro 2).

Quadro 2 - Produção no veículo periódico por extrato: 2007 a 2009

\begin{tabular}{|c|c|c|c|c|c|c|c|c|}
\hline ARTIGOS & $\mathbf{2 0 0 7}$ & $\mathbf{2 0 0 8}$ & $\mathbf{2 0 0 9}$ & $\begin{array}{c}\text { Absoluto } \\
\mathbf{2 0 0 7 - 0 9}\end{array}$ & $\begin{array}{c}\text { Relativo } \\
\mathbf{2 0 0 7 - 0 9}\end{array}$ & Frequência & $\begin{array}{c}\text { Pontuação } \\
\text { CAPES }\end{array}$ & $\begin{array}{c}\text { Peso } \\
\text { CAPES }\end{array}$ \\
\hline A1 & 35 & 36 & 11 & 82 & $4,00 \%$ & & $86-100$ & 100 \\
A2 & 70 & 75 & 71 & 216 & $10,00 \%$ & $14 \%$ & $71-85$ & 85 \\
\hline B1 & 77 & 95 & 94 & 266 & $12,00 \%$ & & $56-70$ & 70 \\
B2 & 98 & 165 & 98 & 361 & $17,00 \%$ & $29 \%$ & $41-55$ & 50 \\
\hline B3 & 92 & 125 & 74 & 291 & $14,00 \%$ & & $26-40$ & 35 \\
B4 & 112 & 125 & 74 & 311 & $15,00 \%$ & & $11-25$ & 20 \\
B5 & 81 & 207 & 123 & 411 & $19,00 \%$ & $48 \%$ & Até 10 & 10 \\
\hline C & 22 & 92 & 72 & 186 & $9,00 \%$ & $9 \%$ & & 0 \\
\hline TOTAL & 587 & 920 & 617 & 2.124 & $100,00 \%$ & \multicolumn{2}{|l}{} & \\
\cline { 1 - 5 }
\end{tabular}

Fonte: Coleta CAPES 2007-2009. 
Tais resultados se dão a partir da adoção de critérios de pontuação pelo comitê da área, constante no "Documento de Área 2009", CAPES -DAV (Divisão de Avaliação) (http://qualis.capes. gov.br/arquivos/avaliacao/webqualis/criterios2007_2009/Criterios_Qualis_2008_36.pdf.) O referido suscita quadro de rankeamento dos periódicos da área (TABELA 2), num total de 785 revistas: $8,00 \%$ delas na frequência $\mathrm{A} 1-\mathrm{A} 2,20 \%$ na B1-B2, $50 \%$ na B3-B5 e $22 \%$ na $\mathrm{C}$.

No presente trabalho apreender-se-á o impacto dos citados periódicos na produção científica brasileira, com a apresentação de cartogramas representativo de seu delineamento no espaço e considerando apenas os extratos mais representativos do estratagema adotado na produção científica em escala nacional : A1, A2, B1, B2, B3 (57,00\% da produção total - Quadro 2).

Tabela 2 - Rankeamento da produção por extrato: Qualis 2007-2009

\begin{tabular}{c|c|c}
\hline EXTRATO & Absoluto & Relativo \\
\hline A1 & 20 & $3,00 \%$ \\
\hline A2 & 41 & $5,00 \%$ \\
\hline B1 & 71 & $9,00 \%$ \\
\hline B2 & 87 & $11,00 \%$ \\
\hline B3 & 110 & $14,00 \%$ \\
\hline B4 & 120 & $15,00 \%$ \\
\hline B5 & 161 & $21,00 \%$ \\
\hline C & 175 & $22,00 \%$ \\
\hline TOTAL & $\mathbf{7 8 5}$ & $\mathbf{1 0 0 , 0 0 \%}$ \\
\hline
\end{tabular}

Fonte: CAPES (http://qualis.capes.gov.br/webqualis/ConsultaPeriodicos.faces).

Como metodologia de trabalho selecionou-se arbitrariamente conjunto de periódicos contidos em cada um dos extratos analisados e capazes de representar tipologias internas. Tais extratos e tipologias (aqui denominada grupos) serão fundamentais na construção da análise e consequente apreensão do comportamento característico da área de geografia.

\section{PERIÓDICOS DA FREQUÊNCIA A: EXTRATOS A1 E A2}

\section{a) Extrato $A 1$}

No extrato A1, a maior produção se concentra na Região Sudeste, principalmente nos estados de São Paulo e Rio de Janeiro, seguidos de Minas Gerais com produção menos representativa. Tal participação nas demais regiões denota quadro no qual o Nordeste assume segunda posição, com importante contribuição do Ceará, seguido de Sergipe, Natal, Paraíba, Pernambuco e Bahia. A terceira posição é ocupada pela Região Sul com participação igual dos estados que a compõem: Paraná, Santa Catarina e Rio Grande do Sul. O Centro-Oeste vem na sequência com produção maior concentrada em Goiás, seguido pelo Distrito Federal e Mato Grosso. Por último temos produção no Norte proveniente do Pará (Figura 3). 

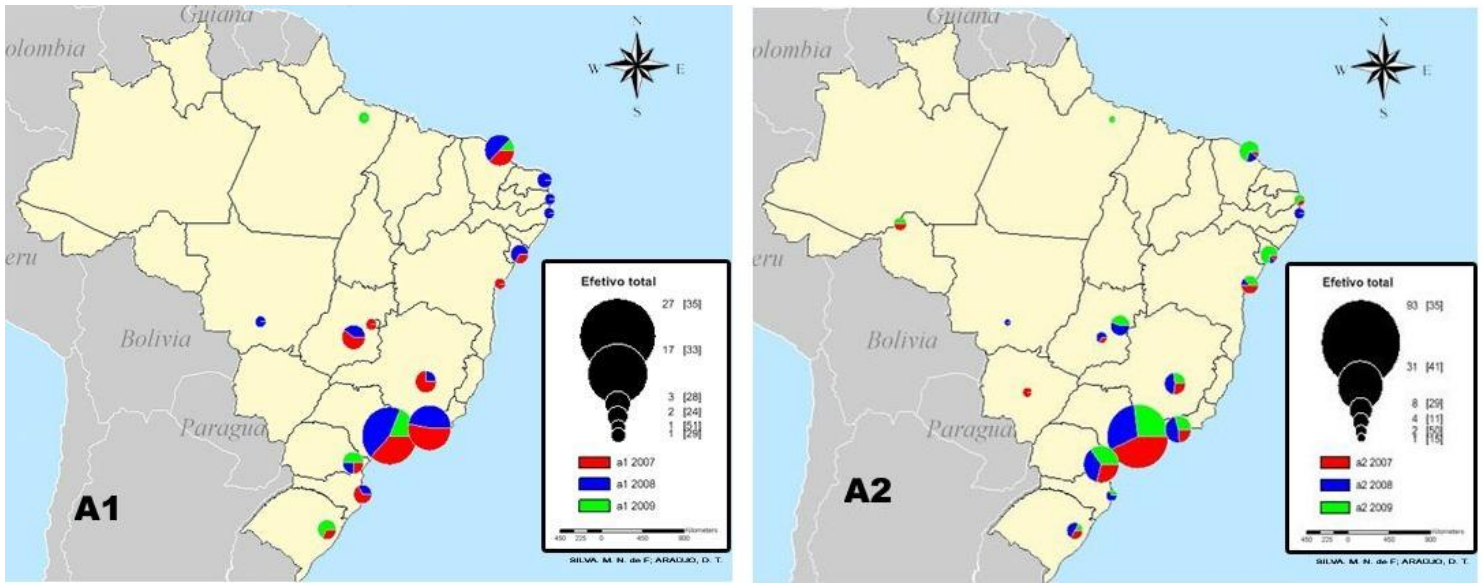

Figura 3 - Total da Produção Docente da Pós-Graduação em Geografia nos Periódicos dos Extratos A1 e A2: Brasil, 2007 a 2009

Fonte: Coleta CAPES 2007-2009

Dentre os periódicos que mais se destacam neste extrato temos constituição de três grupos de matizes linguísticas diferenciadas:

. espanhol: Revista Scripta Nova (Barcelona - 1138-9788);

. francês: Géomorphologie (Paris - 1266-5304) e Hérodote (Paris - 0338-487X);

. inglês: Global and Planetary Change (Print - 0921-8181), International Journal of Remote

Sensing (Print - 0143-1161) e Geophysical Research Letters (0094-8276). (Figura 4)
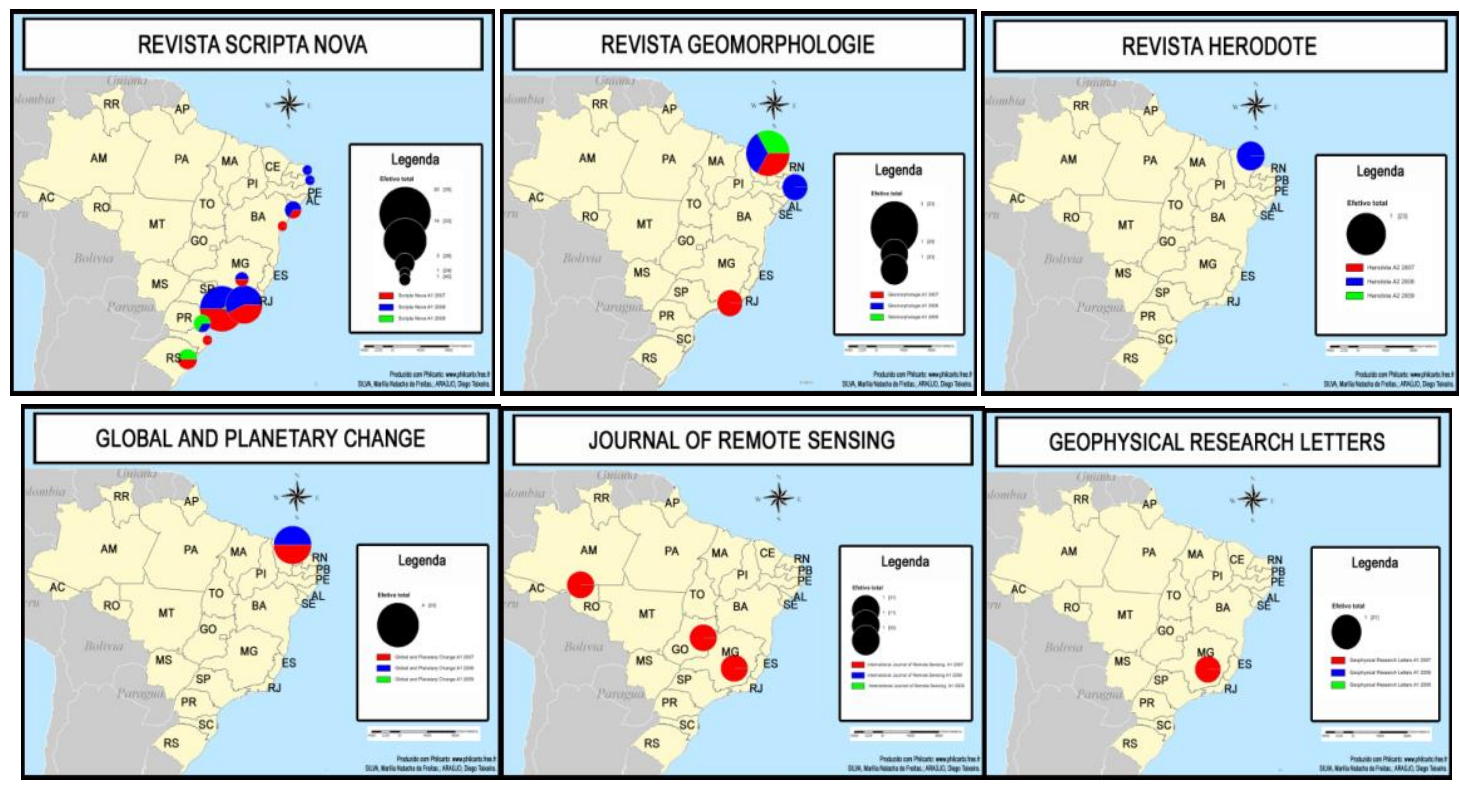

Figura 4 - Produção Docente da Pós-Graduação em Geografia em Periódicos do Extrato A1: Brasil, 2007 a 2009 Fonte: Coleta CAPES 2007-2009

Dentre os citados acima se destaca a Scripta Nova, da matiz espanhola, com produção concentrada principalmente na região Sudeste (São Paulo, Rio de Janeiro e Minas Gerais em ordem de importância) e Sul (Rio Grande do Sul e Paraná, seguidos de Santa Catarina). No Nordeste, papel de destaque é exercido por Sergipe, seguido do Rio Grande do Norte e da Paraíba. 
$\mathrm{Na}$ matiz francesa o destaque é da Géomorphologie, seguida pela Hérodote. Na primeira revista, a maior produção se concentra no Nordeste, ocupando o Ceará papel de destaque e seguido pelo Rio Grande do Norte, com frequncia igual à do sudeste Sudeste (Rio de Janeiro). No segundo periódico há publicação de trabalho do Ceará.

$\mathrm{Na}$ matiz inglesa, a maior produção, direcionada à Global and Planetary Change se concentra no Nordeste (Ceará). A segunda mais importante distribuída igualmente nas regiões Norte (Rondônia), Centro-Oeste (Goiás) e Sudeste (Minas Gerais). Por último, a Geophysical Research Letters com publicação de trabalho de Minas Gerais.

A maior participação dada no periódico Scripta Nova resulta, certamente, da facilidade apresentada no mesmo aos autores lusofônicos, cujos trabalhos são aceitos em sua língua materna.

\section{b) Extrato $A 2$}

No extrato A2, a produção mais significativa se concentra na Região Sudeste, principalmente em São Paulo, seguido pelo Rio de Janeiro e, com menor importância, por Minas Gerais. A segunda região em destaque é a Sul, com produção importante concentrada no Paraná, seguido do Rio Grande do Sul e Santa Catarina. Na sequência se encontra o Nordeste, com destaque para o Ceará, Sergipe e Bahia e, por último, Paraíba e Pernambuco. No Centro-Oeste, a maior participação se dá no Distrito Federal, seguido de Goiás, Mato Grosso do Sul e Mato Grosso. O Norte contribui com menor produção, localizada em Rondônia e Pará (Figura 3).

$\mathrm{Na}$ análise dos periódicos inscritos neste extrato percebe-se dinâmica representativa de três grupos:

. associações/grupos de pesquisa: Geografia (Rio Claro. Impresso - 0100-7912), Terra Livre (0102-8030), Revista Brasileira de Geomorfologia (1519-1540) e Cidades (Presidente Prudente - 1679-3625).

. universitárias: Geousp (USP - 1414-7416)

. matizes linguísticas diferenciadas da lusofônica: a inglesa, com as revistas Catena (Cremlingen - 0341-8162), Journal of Environmental Management (0301-4797); espanhola, a contar com as revistas Investigaciones Geográficas - Instituto de Geografía. Universidad Nacional Autónoma de México (0188-4611) e EURE (Santiago. Impresa - 0250-7161)); francesa, com a revista Espace Géographique (0046-2497). (Figura 5).

No extrato A2 o forte da produção é veiculada em periódicos nacionais, se destacando a GEOUSP, seguida da Geografia de Rio Claro, Terra Livre, Revista Brasileira de Geomorfologia e Cidades.

Na GEOUSP a produção se origina, sobremaneira, do Sudeste e mais especificamente de São Paulo, com pequena participação de Minas Gerais e Rio de Janeiro. A segunda região é a Nordeste, com maior contribuição do Ceará, seguido de Sergipe. O Sul participa fracamente da produção, veiculando paper somente de Santa Catarina.

Geografia de Rio Claro apresenta comportamento diferenciado. Embora tenha menor participação na produção total da área e maior concentração no Sudeste, sua distribuição se apresenta com maior força no Sul, com contribuição maior do Paraná, seguido do Rio Grande do Sul e de Santa Catqarina. No Nordeste também consta-se com produção de Sergipe e Bahia. Para finalizar, no Centro- Oeste tem-se Goiás.

Terra Livre dispõe de contribuição menos significativa, mas a seguir a mesma racionalidade da revista anterior. Concentrada no Sudeste (São Paulo e, com menor contribuição o Rio de Janeiro) e com produção originária também do Nordeste (Paraíba, Ceará e Sergipe) e do Centro-Oeste (Mato Grosso do Sul). 
Sociedade Brasileira de Geomorfologia tem um comportamento diferente das demais. A região a contar com maior produção é a Sul, especificamente o Paraná. Na sequencia se encontra o Sudeste (Minas Gerais, Rio de Janeiro e São Paulo). O Nordeste vem em terceiro, com produção proveniente da Bahia e Rio Grande do Norte. O Centro-Oeste participa com o Distrito Federal e Mato Grosso.

Cidades concentra maior número de contribuições também no Sudeste (São Paulo e Rio de Janeiro), seguida do Sul (Paraná e do Nordeste (Ceará, Bahia e Rio Grande do Norte).

Das revistas provenientes de matizes linguísticas diversas merece destaque a Revista Catena, com produção derivada do Distrito Federal e de São Paulo, seguida do Journal of Environmental Management, com produção em Minas Gerais; Investigaciones Geográficas (RJ); EURE (SP) e Espace Géographique (SP).
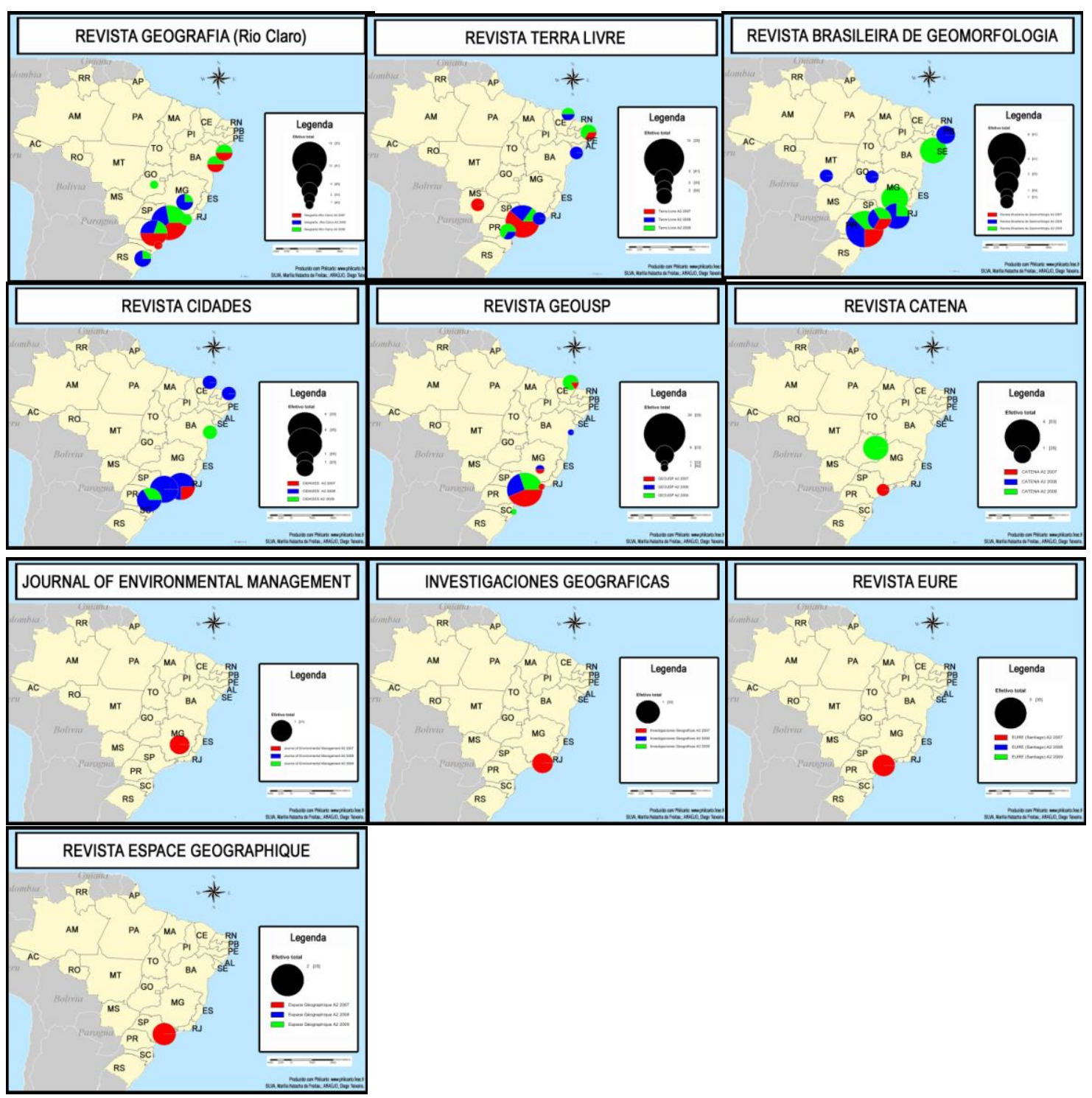

Figura 5 - Produção Docente da Pós-Graduação em Geografia em Periódicos do Extrato A2: Brasil, 2007 a 2009 Fonte: Coleta CAPES 2007-2009

Neste extrato percebe-se claramente maior influência das revistas do gênero universitário e das associações e grupos de estudo, do que as provenientes de matizes linguística diferenciadas. Ademais convém destacar que é neste extrato que se concentra o forte da produção científica melhor qualificada (10,00\% dos trabalhos publicados contra os 4,00\% do extrato A1) na área. 


\section{PERIÓDICOS DA FREQUÊNCIA B: EXTRATOS B1, B2 E B3}

\section{a) Extrato B1}

A concentração maior da produção B1 se situa, em ordem de importância, no Sudeste, (principalmente em São Paulo), Sul (com destaque para o Paraná e, na sequencia, Santa Catarina e Rio Grande do Sul), Nordeste (ênfase percebida no Ceará, com produção notada no Rio Grande do Norte, Paraiba, Pernambuco, Sergipe e, por último, Bahia), Centro-Oeste (Goiânia e Distrito Federal com peso similar) e Norte (pequena participação em Mato Grosso e Pará e fraca na Amazônia e em Rondônia). (Figura 6)

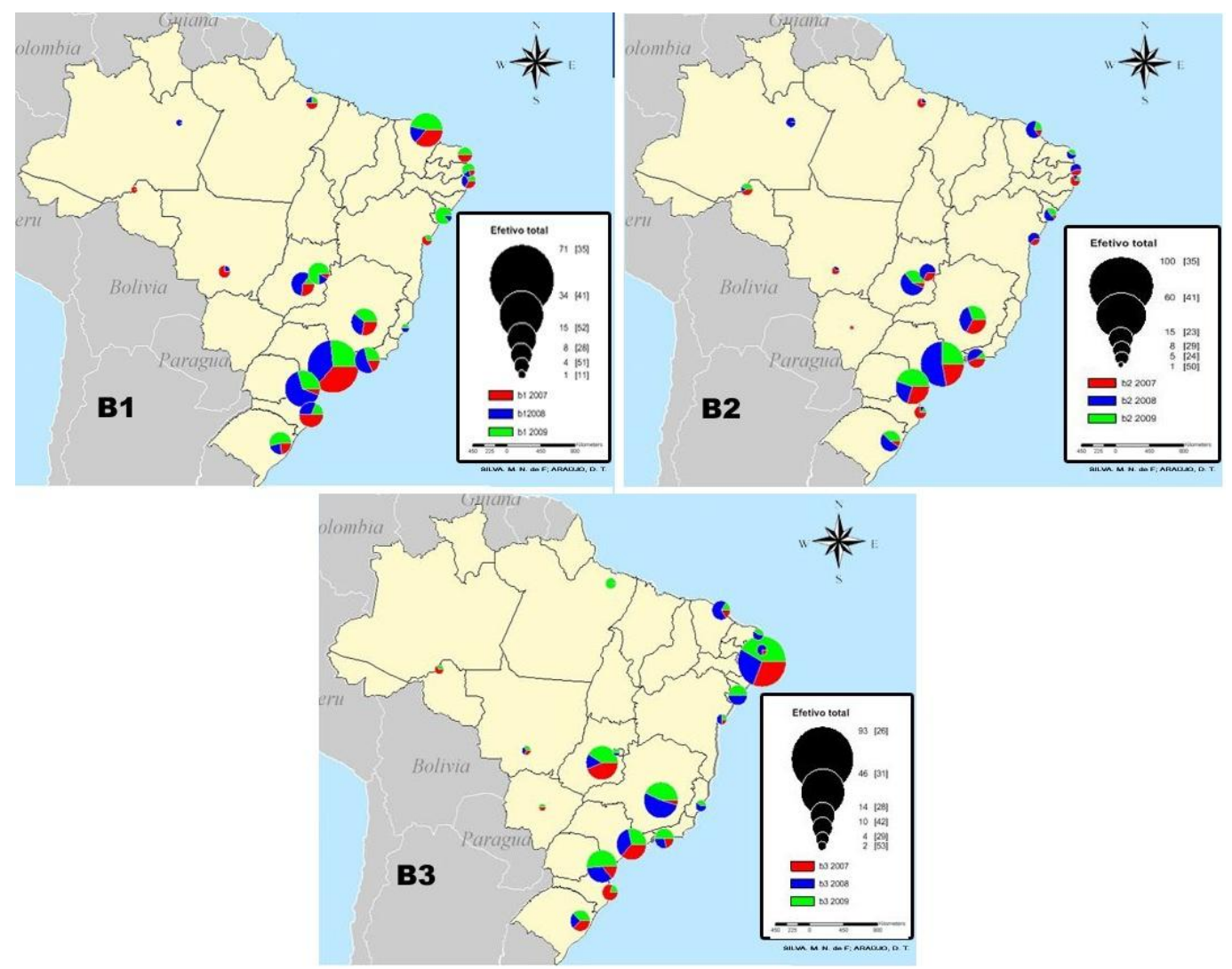

Figura 6 - Total da Produção Docente da Pós-Graduação em Geografia nos Periódicos dos Extratos B1, B2 e B3: Brasil, 2007 a 2009

Fonte: Coleta CAPES 2007-2009

O forte da produção neste extrato se situa em periódicos nacionais. Dele é possível indicar tipologia representativa de três grupos:

. universitárias: Mercator (Fortaleza. Online - 1984-2201) e Geosul (UFSC - 0103-3964);

. associações/grupos de pesquisa: Boletim Paulista de Geografia (0006-6079), Revista Brasileira de Cartografia (Impresso - 0560-4613) e Revista da ANPEGE (1679-768X);

. matizes linguísticas diferenciadas: Journal of Coastal Research (0749-0208)

Dentre as revistas consideradas, a de maior contribuição na produção científica foi a Mercator, seguida do Journal of Coastal Research, da Geosul, Boletim Paulista de Geografia, Revista Brasileira de Cartografia e Revista da ANPEGE (Figura 7). 
Os artigos publicados na Mercator derivam, na ordem de importância, de São Paulo e Ceará. A produção mais importante se situa no Nordeste, com publicação de trabalhos provenientes, além do Ceará, do Rio Grande do Norte, Paraíba, Pernambuco e, em menor proporção, Bahia. Na sequencia temos o Sudeste, com trabalhos originários, além de São Paulo, de Minas Gerais e do Espírito Santo. No Centro-Oeste há a contribuição de Goiás. No Sul trabalhos publicados do Rio Grande do Sul e do Paraná.
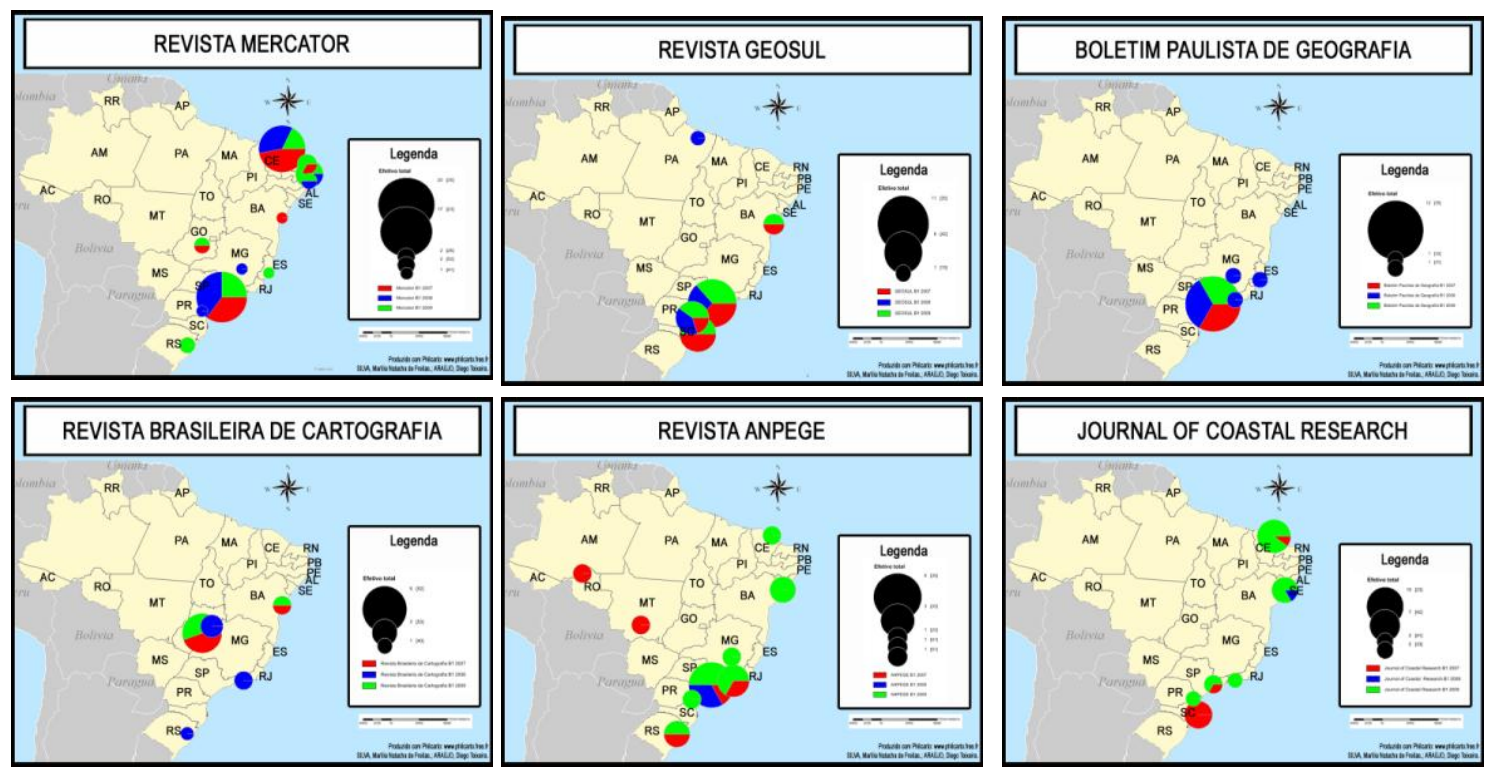

Figura 7 - Produção Docente da Pós-Graduação em Geografia em Periódicos do Extrato B1: Brasil, 2007 a 2009 Fonte: Coleta CAPES 2007-2009

A publicações no Journal of Coastal Research se concentram principalmente no Nordeste, com participação do Ceará e Sergipe. A segunda maior participação se dá no Sul, com trabalhos de Santa Catarina e Paraná. Por último o Sudeste a contar com contribuições de São Paulo e Rio de Janeiro.

A produção da Geosul se concentra no Sudeste e Sul, com participação, em grau de importância, derivada de São Paulo, Santa Catarina e Paraná. Nordeste (Bahia) e Norte (Pará) contam com participação menor.

Boletim Paulista de Geografia tem produção concentrada unicamente no Sudeste, sendo São Paulo o que concentra o grosso da produção, seguido de Minas Gerais, Espírito Santo e Rio de Janeiro, todos com fraca participação.

Revista Brasileira de Cartografia tem sua produção concentrada principalmente no Centro-Oeste, Goiânia e Distrito Federal. As demais regiões, com exceção da Norte, contam com produção da mesma ordem e localizadas nos estados de Bahia, Rio de Janeiro e Rio Grande do Sul.

Revista da ANPEGE concentra maior produção no SUDESTE (São Paulo, Rio de Janeiro e Minas Gerais), seguida do Sul (Rio Grande do Sul e Paraná), Nordeste (Ceará e Bahia em pé de igualdade) e Centro-Oeste (Mato Grosso e Rondônia).

O forte da produção neste extrato se dá em periódicos relacionados às instituições de ensino superior, seguido das revistas de associações e grupos de pesquisa. Por último as revistas de matizes linguísticas diferenciadas.

\section{b) Extrato B2}

A distribuição regional da produção no extrato B2 se concentra com maior importância no Sudeste (São Paulo, Minas Gerais e Rio de Janeiro), seguido do Sul (Paraná, Rio Grande do Sul e Santa Catarina, Centro-Oeste (Goiânia e Distrito Federal, Mato Grosso e Mato Grosso do Sul), Nordeste (Ceará, Sergipe, Rio Grande do Norte, Paraiba, Pernambuco e Bahia) e Norte (Rondônia, Amazonas e Pará). (Figura 6) 
No delineamento da produção científica dos periódicos de geografia neste extrato, percebe-se com maior evidência a problemática da endogenia, detectada em alguns periódicos dos extratos anteriormente tratados.

Em ordem crescente de importância da produção do local de edição no periódico temos: i) Cadernos Geográficos (UFSC - 1519-4639), com toda produção do período proveniente de Santa Catarina; ii) Revista do Departamento de Geografia (USP - 0102-4582), com 50,00\% da produção em São Paulo e o restante no Paraná (Sul); iii) Caderno Prudentino de Geografia (1413-4551), com o grosso da produção concentrada em São Paulo e menor percentual dividido em Rio Grande do Sul (Sul) e Sergipe (Nordeste); iv) Boletim Goiano de Geografia (Impresso - 0101-708X), com sua produção concentrada principalmente no Centro-Oeste, sobremaneira em Goiás, seguido do Mato Grosso do Sul. Em segundo plano se destaca a produção no Nordeste (Ceará e Pernambuco) e, por último no Sudeste (São Paulo e Rio de Janeiro); v) Confins (Paris - 1958-9212), o forte de sua produção se situa em São Paulo (Sudeste), mas convém destacar importância dos trabalhos do Sul (Paraná e Rio Grande do Sul) e, na sequencia no Nordeste (Ceará e Rio Grande do Norte); vi) Ra'e ga (UFPR - 1516-4136) concentra sua maior produção no Sul, principalmente no Paraná e com menor força no Rio Grande do Sul, seguido do Sudeste (São Paulo e Minas Gerais), Nordeste (Ceará, Rio Grande do Norte e Sergipe) e no Centro-Oeste em Goiás; vii) Sociedade \& Natureza (UFU. Online - 1982-4513), também concentra sua maior produção no Sudeste, principalmente em Minas Gerais e seguido por São Paulo. Convém destacar importante produção no Sul (Paraná), e de menor importância no Centro-Oeste (Goiânia) e, por último, no Nordeste (Ceará); viii) Espaço e Cultura (UERJ - 1413-3342) representa a exceção à regra, nela percebe-se um equilíbrio na distribuição espacial da produção. Paraná (Sul) com produção superior à do Rio de Janeiro, que por sua vez se iguala à da Bahia (Nordeste). Com igual peso da produção em São Paulo (Sudeste), temos a produção de Rondônia e Amazonas. (Figura 8).

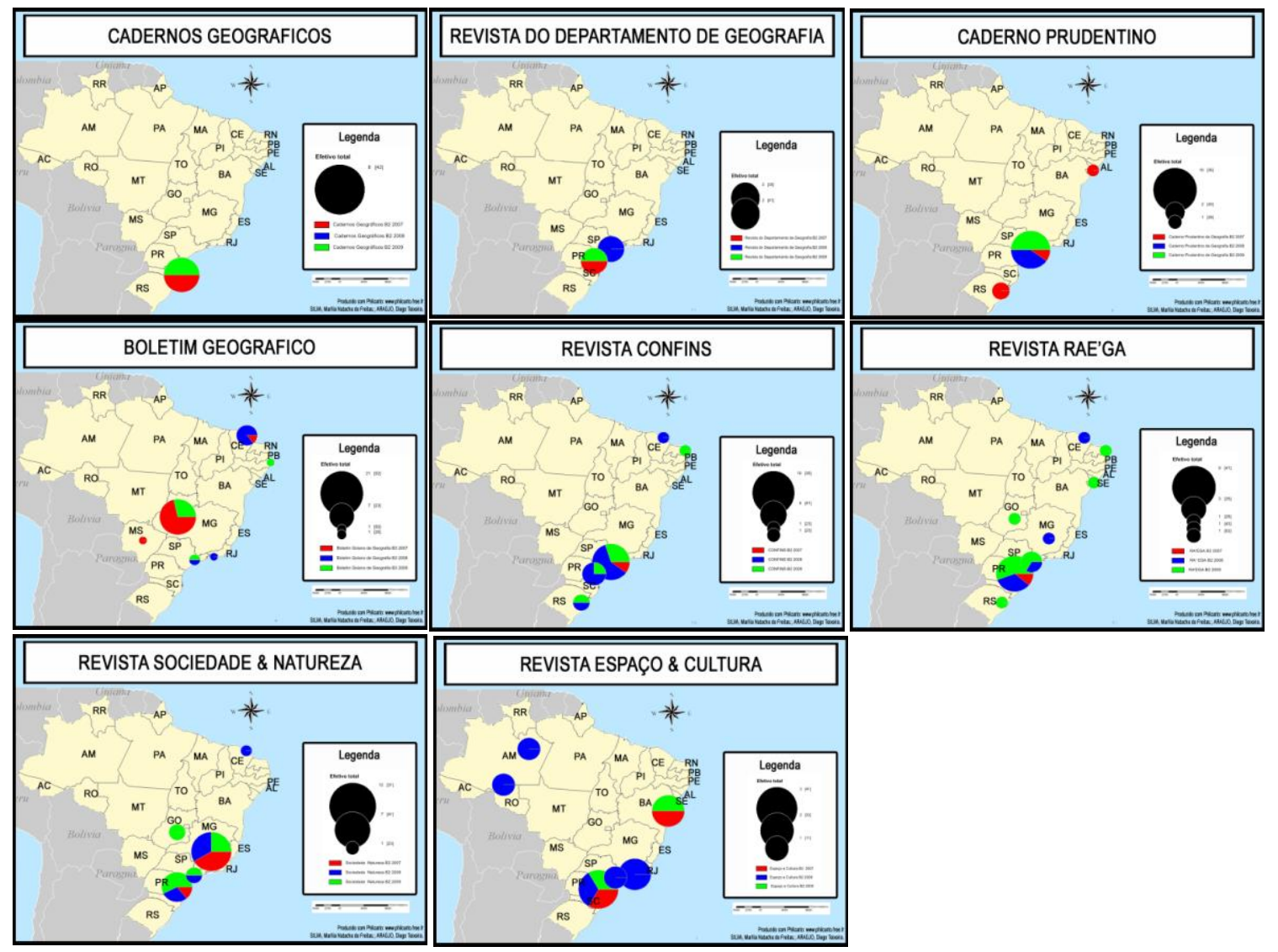

Figura 8 - Produção Docente da Pós-Graduação em Geografia em Periódicos do Extrato B2: Brasil, 2007 a 2009 Fonte: Coleta CAPES 2007-2009 
A explicação para este gênero de comportamento certamente se deve à natureza das revistas. A maioria delas é do gênero acadêmico, diferentemente da última revista, derivada de um grupo de pesquisa.

\section{c) Extrato B3}

$\mathrm{Na}$ consideração da distribuição da produção científica do extrato B3 chama a atenção concentração importante de papers em Recife, dando destaque ao Nordeste (contendo menores participações em Sergipe, Ceará, Rio Grande do Norte, Paraíba e Bahia) em relação a outras regiões. A segunda região em destaque é a Sudeste (Minas Gerias, São Paulo, Rio de Janeiro e Espírito Santo). Em terceiro lugar o Sul (Paraná, Santa Catarina e Rio Grande do Sul). Quarta classificação o Centro-Oeste (Goiânia, Distrito Federal, Mato Grosso e Mato Grosso do Sul). Na última posição o Norte (Rondônia e Pará). (Figura 6).

Do quadro acima descrito deriva perfil característico de conjunto de revistas acadêmicas com forte influência da Revista de Geografia (Recife - 0104-5490) na produção científica em escala local, seguida de outro conjunto de revistas cuja endogenia é menos presente e indicada em ordem de importância: Geo UERJ (1415-7543) e Geonordeste (UFS - 1518-6059) no mesmo patamar e Ateliê Geográfico (UFG - 1982-1956) com menores implicações. (Figura 9)
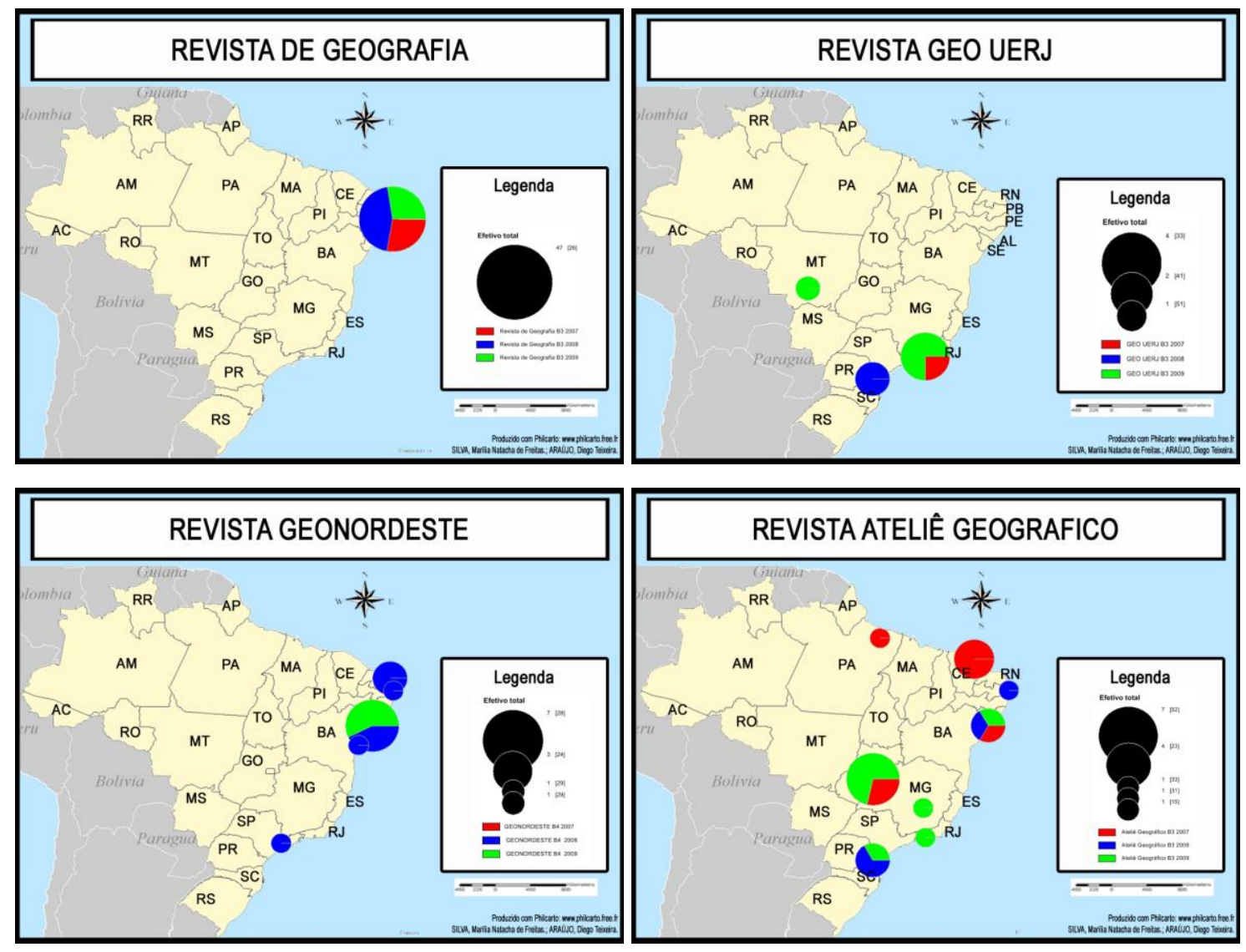

Figura 9 - Produção Docente da Pós-Graduação em Geografia em Periódicos do Extrato B3: Brasil, 2007 a 2009 Fonte: Coleta CAPES 2007-2009

A produção computada na Revista de Geografia de Pernambuco é originada exclusivamente do lugar, apresentando movimento peculiar, considerando o volume da produção envolvida no quadro comportamental dos periódicos brasileiros da área de geografia.

Geo UERJ tem o forte da produção originária do Rio de Janeiro, dispondo de algumas contribuições do Paraná (Sul) e Mato Grosso (Centro-Oeste). 
Geonordeste apresenta comportamento próximo, concentrado em Sergipe, mas a contar com papers provenientes de outros estados do Nordeste (Rio Grande do Norte, Paraíba e Bahia) e do Sudeste (São Paulo).

Ateliê Geográfico se apresenta como exceção relativa à regra. Embora replique forte concentração no local de editoração (Goiânia - Centro-Oeste), percebe-se claramente uma razoável contribuição do Nordeste (Ceará, Bahia e Paraíba), Sul (Paraná), Sudeste (Rio de Janeiro e Minas Gerais) e, por último, Norte (Pará).

\section{CONSIDERAÇÕES FINAIS}

Consoante à mudança de mentalidade empreendida na área, e reflexo das diretrizes postas na pós-graduação, os periódicos foram transformados em entidades estratégicas na produção de conhecimento científico. Não é de estranhar haver uma relação direta entre o quantitativo da produção científica em dada localidade ou região e a existência de veículos desta natureza. O peso da produção A2 no Sudeste e de São Paulo em especial, coincide com presença de periódicos inseridos neste extrato (GEOUSP, Geografia de Rio Claro e Cidades). Este dado não é tão visível, em termos quantitativos, quando consideramos as revistas de matizes linguísticas diferenciadas. Também destacamos movimento próximo em outros extratos: i) importante produção no Nordeste e Sul no extrato B1, mais especificamente no Ceará e Santa Catarina, associada à Mercator e Geosul; produção significativa no Centro-Oeste e Sul relacionada, respectivamente, ao Boletim Goiano e à RA\&Ga, ambas B2.

Conhecedor desta importância urge tomar cuidado no sentido de que esta importância não culmine em endogenia. Em suma, numa produção tão marcadamente local que pode suscitar: arrefecimento das possibilidades de trocas, com inclusão de trabalhos provenientes de outros estados e regiões; e, no futuro, morte do próprio periódico. Merece atenção neste sentido, delineamento de estratégia editorial implementada principalmente nos periódicos B3, exemplo extremo é o da Revista Geografia de Pernambuco, seguida da Geouerj. No entanto este dado não se restringe a este extrato. Mesmo sendo nele onde os problemas são maiores, convém chamar a atenção, em ordem de gravidade, aos Cadernos Geográficos (B2), Boletim Paulista (B1) e GEOUSP (A2). Mais sério ainda é a constatação de a maioria dos periódicos citados serem do gênero revista universitária: associada às Instituições de Ensino Superior ou às Pós-Graduações em Geografia.

Necessário se torna romper com a postura amadorística reinante na área. Interessante construir uma política agressiva de editoração de periódicos, capaz de extrapolar o raio de influência dos cursos e adentrar no da nossa associação de pós-graduação (ANPEGE). Ações neste sentido já foram implementadas, como a da organização do Fórum dos Editores de revistas da Pós-Graduação em Geografia. Necessário dar continuidade e contribuir na construção de um projeto de editoria na e para a área.

Neste sentido não podemos deixar de considerar as possibilidades de:

i) assimilação da lógica de indexação à editoração dos periódicos, direcionando esforços no sentido de qualificar os veículos atualmente existentes. $\mathrm{Na}$ área das ciências sociais existe inclusive a possibilidade de vinculação a indexadores nacionais (SCIELO) ou do continente (REDALYC). Neste domínio existe ainda uma grande timidez da área. Somente um periódico participa da Scielo (Sociedade e Natureza). Nos mesmos termos a Revista Geografia de Rio Claro também consta dentre os associados à REDALYC. Lamentavelmente, não é vislumbrado ainda movimento significativo no sentido de reverter este quadro;

ii) incorporação, ao horizonte da geografia brasileira, de periódicos internacionais qualificados. A tradição da Geografia Humana internacional, em não primar na arte da indexação, torna esta tarefa difícil. Diferentemente, percebe-se maior facilidade na Geografia Física, a poder usufruir de conjunto de periódicos com alto fator de impacto das Geociências. Embora exista 
sempre o recurso às traduções, a situação se agrava para as duas áreas em função da barreira linguística. A participação em periódicos da matiz espanhola, abertos à textos em português, somente adia o inadiável. É notória, em termos relativos, a pouca produção científica em outras línguas, dado explicador do fraco percentual atribuído na pontuação total dos periódicos A1 $(4,00 \%)$.

iii) Formalização e profissionalização da arte de produzir periódicos. Neste domínio a editoria e o papel dos editores na veiculação do conhecimento produzido não é negligenciável. Esta dimensão é fundamentalíssima no encaminhamento e êxito nas estratégias de implementação do primeiro ponto.

Necessitamos rever postura ainda propalada na geografia e não permeada pela noção de alteridade. Discursos ideologizados tendem ignoram completamente existência de discussão sobre o veículo periódico em escala internacional e suscitam quadro no qual se torna impossível pensar em contraestratégias. Ponderar se entende como capitular, dado a justificar o abandono do campo político no qual a diemnsão da produção científica é gestado. Grosso modo, a da tomada de consciência de que existe um embate entre os campos do conhecimento humano e no qual o approche das Ciências Duras se fortalece.

O filtrado como fragilidade, o não atender aos termos das ciências duras, possibilita, de fato, geração de quadro a ser explorado pelas ciências sociais e no sentido de fortalecer suas matizes. No Basil, o "Qualis Livro" pode ser entendido como uma conquista parcial, outra a ser construida é no domínio das indexações dos periódicos, com o refinamento do olhar dos profissionais da área em relação à estruturação deste veículo. Um olhar que não pode e nem deve abdicar da idéia de universalidade da ciência. A ação transformadora somente se efetivará após apresentação desta ou de outras contrapropostas ao estabelecido e não na pura e simples negação.

\section{BIBLIOGRAFIA}

SILVA, José Borzacchiello da; DANTAS, Eustógio Wanderley Correia. A Pós-Graduação em Geografia no Brasil: uma contribuição à política de avaliação. Revista da ANPEGE, n. 2, 2005.

CAPES. Cadernos de Indicadores (2207 a 2009). Acesso: http://conteudoweb.capes.gov.br/conteudoweb/ CadernoAvaliacaoServlet.

CAPES. Documento de área. Acesso http://qualis.capes.gov.br/webqualis/ConsultaPeriodicos.faces.

Trabalho enviado em agosto de 2011 Trabalho aceito em outubro de 2011 